\title{
Erratum to: "Atmospheric Carbon Monoxide Dynamics over Kazakhstan Derived from Satellite Data" [Russian Meteorology and Hydrology 45(1), 54-57, 2020]
}

\author{
A. Kh. Akhmedzhanov ${ }^{a *}$ and T. K. Karadanov ${ }^{a}$ \\ ${ }^{a}$ National Center of Space Research and Technology, Aerospace Committee, \\ Ministry of Digital Development, Innovations, and Aerospace Industry of the Republic of Kazakhstan, \\ ul. Shevchenko 15, Almaty, 050010 Kazakhstan \\ *e-mail:model_lab@mail.ru \\ Received August 14, 2018 \\ Revised February 14, 2019 \\ Accepted June 4, 2019
}

DOI: $10.3103 / \mathrm{S} 1068373920040111$

In this article the true title is

\section{Atmospheric Carbon Monoxide Dynamics over Kazakhstan Derived from Satellite Data}

The original article can be found online at 10.3103/S1068373920010070. 